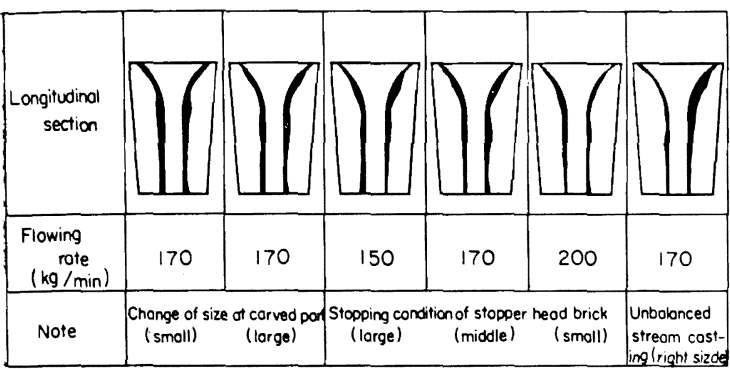

Fig. 4. Longitudinal section of nozzle brick after casing (Nozzle : No B in Table 1)

場合, ストッパーの絞り程度は少なくなる。 ノズル上層 部，および“湯のかえり”部分の溶損は絞り程度を強く すると大きくなる，また，最後の図から，少しのストッ パー偏心で溶損された方に大きく影劕することが認めら れる. 以上のことは，ノズルとストッパーの相互位置, 鋳造条件，ノズルロ径の選定の重要性に結びつく.

\section{3. 結語}

中炭素鋼を対象に種々の材質のノズル煉瓦を使用し， 比較試験を行なつた結果，下記の事項が認められた。

1) 種々のジルコン質ノズルを使用した結果, $\mathrm{ZrO}_{2} \%$ の減少とともに溶損率は増大寸る。一方，60\%以上のジ ルコン質は, 溶損率においてジルコニア質に匹敵する. 粘土質, 高丁ルミナ質などは $\mathrm{ZrO}_{2}$ 采ノズルに比べ溶損 率は大きい。ク口ム処理，および $\mathrm{SiC}$ 添加によつてあ る程度の耐溶損性の向上が認められた。

2)ノズルの溶損は，ストッパーの絞り，偏心，およ びノズル形状により影響されることが大である.

3) Wettability, ズル内面付着状況は, ジルコン質, ジルコニフ質は，他の材質より良好である。

4）以上の試験結果と各材質のコストを考えた場合, 高価なジルコニフ質の使用は必要なく, 普通のジルコン 質でも十分使用に耐え，さらには，50\%前後の $\mathrm{ZrO}_{2}$ 含 有量のものでも満足な鋳造が得られる.

5) シャモット質の溶損は，ジルコン質，ジルコニフ 質よりかなり大きいが，安洒であること，逆に鋳込末期 の温度低下，および内面付着物などによる口径縮少現象 を相殺するということなどの利点がある．溶損物の鋳片 表面欠陥に与える影響の点があると考えられ，さらに， これの使用試験を進めたい。

5) 使用前後における煉瓦の組織的研究，溶損特性お よび溶損生成物の鋳片表面性状に与える影噌などの研究 を今後, 進的ていくつもりである.

\section{交献}

1) 京藤: 宗宮: レアナタル, No. 23, p. 42

$$
\text { 一討論一 }
$$

[兵問] 神鋼中研 鈴木 武

1. 実験に用いたノズル形状，大きさは $\mathrm{A} 〜 \mathrm{I} （ 9$ 種 とも）まで全く同じものを使用したものか，できれば寸 法を知りたい.

2. Fig. 1のデータ errosion loss \%で示された值は 実験後のノズル界面に生じる变質層厚みを含むのか．

[回答]
1. Table 1 に示した各種ノズル形状，大きさは 全く同じものを使用しました。ただし，Fig. 4 に示 したようにノズル形状による溶損状沉の究明に対し ては, 朝顔部の形状, 寸法の相異なるものを使用し た.

2. 実験後の溶鋼との接触面において，反応およ び焼結による变質層は必ず認められるが，溶損率に はこの厚みを含えでいない。

この变質層については, 使用前後の棟瓦における 組織的研究, 溶損特性などの解明に考虑し, 別途, 試験を進めていくつもりである.

\section{ニオブ添加鋼における添加剤とし てのニオブカーバイトとフェロニ オブの比較}

東京工業大学工博田中良平

(株) 鉄興社

理博 林 瑛·川上 登. ○福元順治郎 Comparison of $\mathrm{Nb}$-Carbide to Ferro-Nb as a Adding Reagent in Nb-Added Steels Dr. Ryöhei Tanaka, Dr. Akira Hayashi Noboru Kawakami and Junjirö Fukumoto

\section{1. 緒}

言

最近，米国およびわが国において，0.05\%程度の微量 の $\mathrm{Nb}$ 老添加した引張強さ $50 \sim 60 \mathrm{~kg} / \mathrm{mm}^{2}$ の高張力 鋼が開発され，すでにかなりの量が市販されている。こ れらの含 $\mathrm{Nb}$ 鋼製造に南たつておもに用いられている Nb添加戍は Ferro-Nb であるが，これは高価な $\mathrm{Al}$ を 還元剂に使用すること，スラグへの有効成分の損失や強 度の粉砕整粒にともなう手数およびサイジングロスなど 生産性, 経済性のうえで問題がある。また, これを溶鋼 に添加した場合之の比重（見掛比重 8.2）方溶鋼より大 きく鋼㳂下に沈えでしまうため実際使用上とくに注意を 要し, 前記のサイジングの強化もこの点に関連して必要 とされるわけである。

一方, ニオブカーバイト（以下 Nb-C と略記する）は 二の比重が若干小さい（見掛比重的 $5 \cdot 4$ 前後）た的，取 鍋に添加しても底部に沈えで鋳込後に取鍋の底に残留す るようなことがなく，また Nb-C 中の炭素が $\mathrm{Nb} の$ 酸

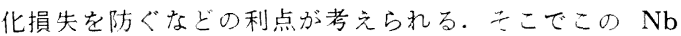
添加剂としての Nb-C の実用性を検討するため $3 \mathrm{~kg}$ お よび $100 \mathrm{~kg}$ 溶解の規模で, †の溶鋼一の溶解性や歩留 りを調査して Ferro-Nb 添加の場合と比較し, さらにこ れらの鋼塊を熱間圧延して得た鋼材の組織や機械的性質 についても検討した。

\section{2. 試料および実験方法}

$2 \cdot 1 \mathrm{Nb}$ 添加刘

本実験に使用した Nb 添加抄の化学組成は Table 1 に示すとおりである。

$2 \cdot 2$ 溶解性試験

溶解性試験の場合は，Nb-C-および Ferro-Nbの両方 とも放電加工により $10 \times 6 \times 60 \mathrm{~mm}$ （溶湯中浸漬部の長 
Table 1. Chemical composition of $\mathrm{Nb}$-adding reagents $(\%)$

\begin{tabular}{|c|c|c|c|c|c|c|}
\hline $\begin{array}{l}\mathrm{Nb} \text {-adding } \\
\text { reagents }\end{array}$ & $\mathrm{Nb}$ & Ta & C & Si & $\mathrm{Mn}$ & $\mathrm{Fe}$ \\
\hline $\mathrm{Nb}-\mathrm{C}$ & $60 \cdot 15$ & $5 \cdot 27$ & $10 \cdot 1$ & - & $0 \cdot 77$ & $19 \cdot 9$ \\
\hline Ferro-Nb & $65 \cdot 00$ & $5 \cdot 75$ & $0 \cdot 03$ & $0 \cdot 78$ & $1 \cdot 58$ & $25 \cdot 8$ \\
\hline
\end{tabular}

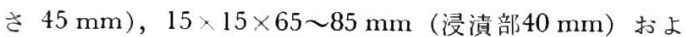
び $20 \times 20 \times 75 \mathrm{~mm}$ (浸湞部 $60 \mathrm{~mm}$ ) の角柱状に切り出 したものを用いた。溶解は $3 \mathrm{~kg}$ の问周波炉を使用し て, 電解鉄と高純度銑鉄 $(3 \cdot 85 \% \mathrm{C})$ を融解した後，Si お上ご Mn で脱酸し， $0.16 \% \mathrm{C}, 0.06 \% \mathrm{Si}, 1.20 \% \mathrm{Mn}$,

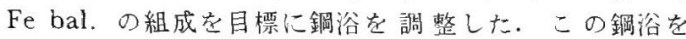
1580 C に保定し，前記の Nb 添加刜を重直方向に浸清 して，10 sec または $15 \mathrm{sec}$ 保持した後，取り出して空 冷し，付着した鉄分を研削および塩酸処理て除去して溶 け残つた角柱の重量を測定し，浸漬部分の重量に対する 溶解減量 $(\%)$ を求めた。

$2 \cdot 3$ 機械性試験用鋼材の調製

これに用いた $\mathrm{Nb}$ 添加绪の粒度は，Nb-C では 1〜5 $\mathrm{mm}$, 5〜 $10 \mathrm{~mm}$ および 10 20 $\mathrm{mm}$ の 3 種類とし，ま た Ferro-Nb は 1〜5 mm および 5〜10 mm の 2 種類 を用意した。溶解は $100 \mathrm{~kg}$ の高周波炉を使用して，溶 解性試験の場合と同じ配合組成の鋼浴を眮整し，鋼浴温 度約 $1600 \mathrm{C}$ で取鍋なたは炉中に，0.06\% Nb を目標と

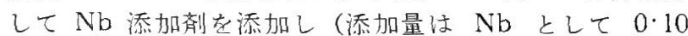
\%) 利 $1 \mathrm{~min}$ 鎮静後, $50 \mathrm{~kg}$ 角形鋳型に注入した。 こ

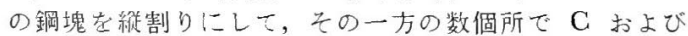
Nbを分析して偏析の程度を調べた。

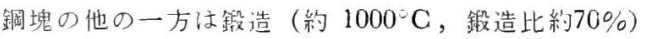
により $25 \mathrm{~mm}$ 角のビレットとし，これを $1230 \mathrm{C} \mathrm{lhr}$ 加熱して，厚さ $7 \sim 8 \mathrm{~mm}$ まで約 $700^{\circ}$ 。の熱間圧延を行 なつた，圧延終了温㡶は約 $850^{\circ} \mathrm{C}$ に一完し，二の後空 冷した。この熱延村から平行部寸法 $15 \times 6.60 \mathrm{~mm}^{3}$ の 引張試略片および $6 \times 10 \times 55 \mathrm{~mm}^{3}$ のソ/ッチシャルヒ 一試䮖片在多数切り出して実験に供した。供諘莳の代表 的な化学組成を Table 2 に示す、比竷のため Nbを添 加しない・䑚A も同様の工程で用意した.

\section{3. 実 験 結 果}

$3 \cdot 1 \mathrm{Nb}-\mathrm{C}$ および Ferro-Nb の鋼浴一の溶解性

$1580^{\circ} \mathrm{C}$ で $10 \mathrm{sec}$ おび $15 \mathrm{sec}$ の試験で溶け残つた $\mathrm{Nb}$ 添加剂の状況を Photo. 1 に, またそれらの溶解減 量を Table 3 に示した. Nb 添加物の断面寸法が小さ い場台は，Nb-C と Ferro-Nb の溶解隇量にはほとえ ど差が認められない，しかし添加物の断面寸法が大きく なるにつれて产美が明らかとなり，たとえば $20 \times 20 \times$

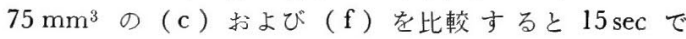
Ferro-Nb の溶解減量がわずか $13 \%$ に過ぎないのに対

Table 2. Chemical composition of steels used $(\%)$.

\begin{tabular}{c|c|c|c|c|c}
\hline \hline Mark Nb-adding reagents & Nb & $\mathrm{C}$ & $\mathrm{Si}$ & $\mathrm{Mn}$ \\
\hline $\mathrm{A}$ & - & - & $0 \cdot 153$ & $0 \cdot 09$ & $1 \cdot 32$ \\
$\mathrm{~B}$ & Ferro-Nb & $0 \cdot 10$ & $0 \cdot 160$ & $0 \cdot 07$ & $1 \cdot 33$ \\
$\mathrm{C}$ & $\mathrm{Nb}-\mathrm{C}$ & $0 \cdot 10$ & $0 \cdot 153$ & $0 \cdot 09$ & $1 \cdot 37$ \\
\hline
\end{tabular}

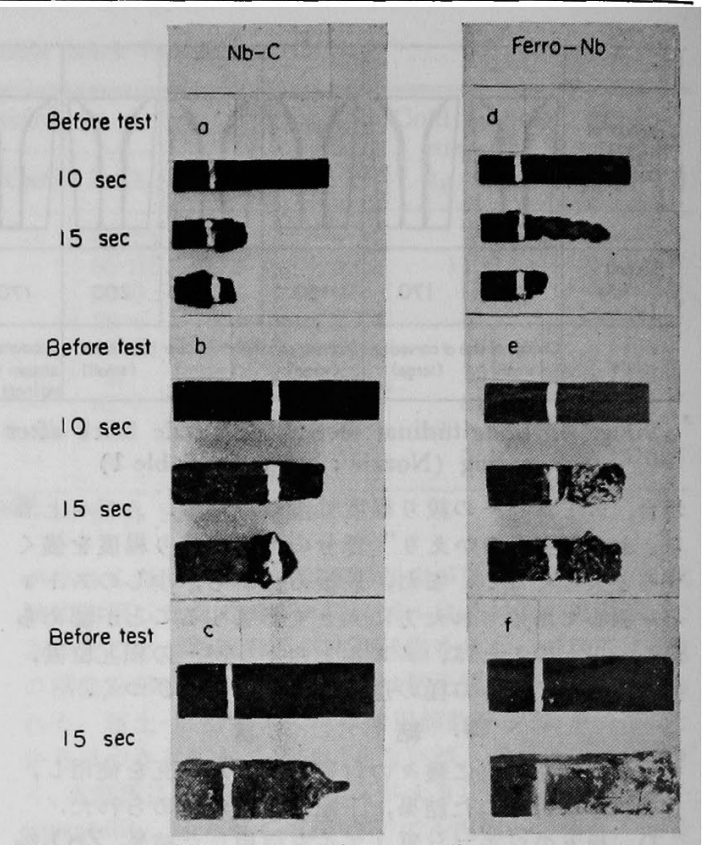

Photo. 1. Melting test of $\mathrm{Nb}$-adding reagents into molten steel.

Table 3. Melting test of $\mathrm{Nb}$-adding reagents into molten steel.

\begin{tabular}{|c|c|c|c|c|}
\hline \multirow{2}{*}{$\begin{array}{l}\text { Nb-adding } \\
\text { reagents }\end{array}$} & \multirow{2}{*}{ Mark } & \multirow{2}{*}{$\begin{array}{l}\text { Volume of } \\
\text { dipped } \\
\text { part ( } \mathrm{mm})\end{array}$} & \multicolumn{2}{|c|}{$\begin{array}{l}\text { Decrease in wt. of } \mathrm{Nb}- \\
\text { adding reagents }(\%)\end{array}$} \\
\hline & & & $\begin{array}{l}10 \text { sec } \\
\text { dipped }\end{array}$ & $\begin{array}{l}15 \mathrm{sec} \\
\text { dipped }\end{array}$ \\
\hline $\mathrm{Nb}-\mathrm{c}$ & $\begin{array}{l}\text { (a) } \\
\text { (b) } \\
\text { c })\end{array}$ & $\begin{array}{l}10 \times 6 \times 45 \\
15 \times 15 \times 40 \\
20 \times 20 \times 60\end{array}$ & $\begin{array}{l}68 \\
68 \\
-\end{array}$ & $\begin{array}{l}75 \\
90 \\
43\end{array}$ \\
\hline Ferro-Nb & $\begin{array}{l}\text { (d) } \\
\text { (e) } \\
\text { (f) }\end{array}$ & $\begin{array}{l}10 \times 6 \times 45 \\
15 \times 15 \times 40 \\
20 \times 20.60\end{array}$ & $\begin{array}{l}67 \\
56 \\
-\end{array}$ & $\begin{array}{l}85 \\
58 \\
13\end{array}$ \\
\hline
\end{tabular}

Marks : (a), (b) -..(f) arc corresponded to marks in Photo. 1, respectively.

し， Nb-C はその 3 倍強の $43 \%$ がすでに溶解してお り， Nb-C の溶解速度がかなり大いことを示してい る.

\section{$3 \cdot 2 \mathrm{Nb}$ の歩留りおよび偏析}

$50 \mathrm{~kg}$ 銅塊の各部で， Cおよび $\mathrm{Nb}$ を分析した。その 数例を Fig. 1 に示したが，Nb-C， Ferro-Nb のいず れの場合にもCはややばらついているが $\mathrm{Nb}$ の偏析はほ とえど認められず，また各部の $\mathrm{Nb} \%$ は $0.08 〜 0.10 \%$ であつて配合值 $0 \cdot 10 \%$ に対して歩留りはほぼ十分であ り，かっ Nbの添加戍の種類による違いはみられなかつ た.

\section{$3 \cdot 3$ 組織および機械的性質}

\section{3 .1 組㦻}

$\mathrm{Nb}$ が鋼の結晶粒を微細化する作用はアルミキルド鋼 でもすでによく知られている1つ 3)が本実験です鐉造材を

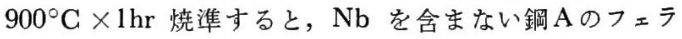




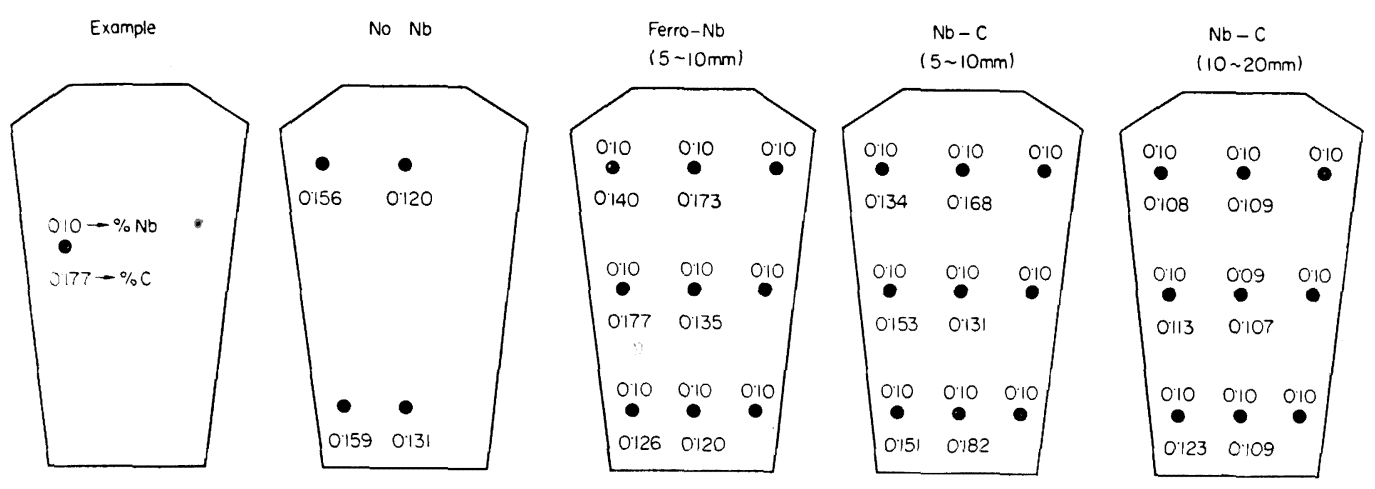

Fig. 1. Segregation of $\mathrm{Nb}$ and $\mathrm{C}$ in $50 \mathrm{~kg}$ ingots.

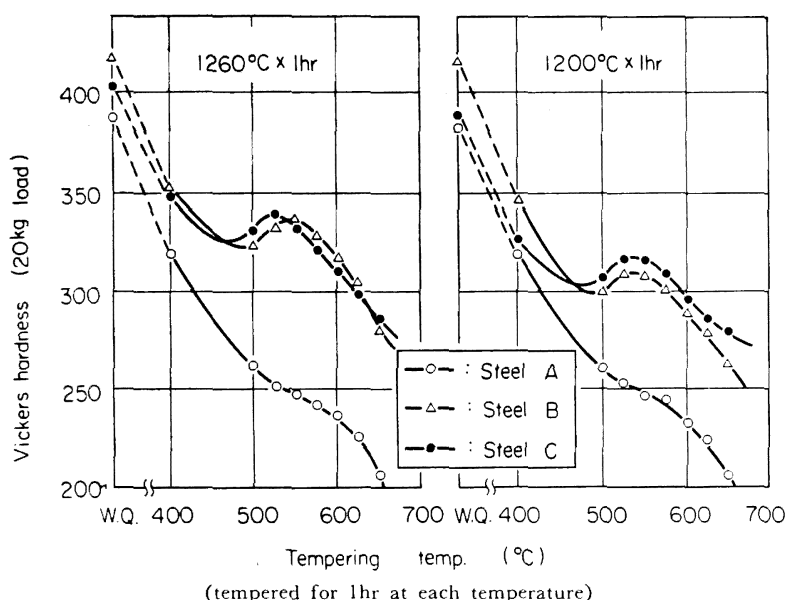

Fig. 2. Precipitation hardening of $\mathrm{Nb}$ treated steels.
$3 \cdot 3 \cdot 2$ 焼戻し硬さ

各鋼を $1100 \sim 1260^{\circ} \mathrm{C}$ の各温度から溶体化焼 入れ後, $400 \sim 650^{\circ} \mathrm{C}$ の崭囲に焼戻して硬さの 变化を調べたが，B， C兩鋼の析出硬化挙動は Fig. 2 にみるように，多くの研究者)によつて 報告されているものとほぼ同栏で，いずれも 525 550 $\mathrm{C}$ で最高硬度を示し, かつ溶体化処 理温度が高いものほど，硬化が顕著となる。

$3 \cdot 3 \cdot 3$ 機械的性質

A， B， C 各鋼の機械的性質のうち代表的な 数值を Table 4 に示した。これらの数值はい ずれの鋼も $1230^{\circ} \mathrm{C}$ から $850^{\circ} \mathrm{C}$ まで熱間圧延 後空泠したままのものであるが，Nbを含まな いAに比べてBおよびCはともにすぐれた機械 的性質を有しており，かつ，これらの值は一般 に報告されているものと同程度の值を示してい $\Xi^{6)}$. とくに降伏点の上昇は大きく降伏比が著 しく増加しているが，Nb 添加剤の違いによる 引張試験結果の差異は認められない。

また，シャルピー衝整試験による遷移温度曲線をFig. 3 に示した。便宜的に衝整值が靶性状態の值より半減す る温度で遷移温度を表わせば Table 4 中に記入したよ うに， $\mathrm{Nb}$ を含まない鋼 $\mathrm{A} の-70^{\circ} \mathrm{C}$ に比して $\mathrm{B}$ および $\mathrm{C}$ はを机ごれ， $-20^{\circ} \mathrm{C}$ おび $-25^{\circ} \mathrm{C}$ となり, $\mathrm{Nb}$ 添加

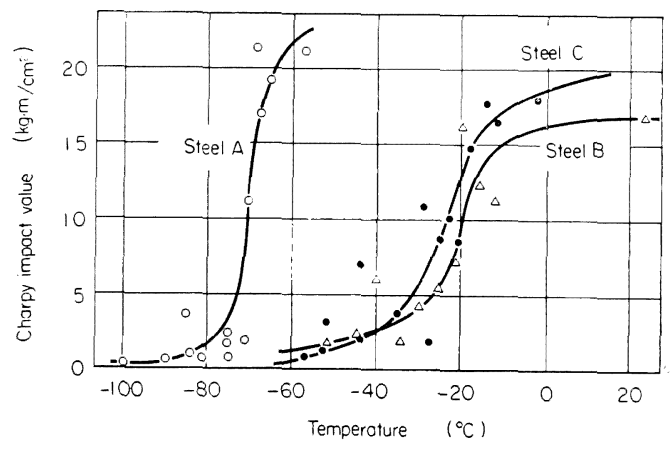

Width of $\mathrm{V}$ notch Charpy impact : $6 \mathrm{~mm}$

Fig. 3. Charpy impact test of hot rolled steels. $(10 \mathrm{~kg}$ )
も少量の NbC が残存することはありうるものと考えら れる。 
Table 4. Results of tension test and impact test.

\begin{tabular}{c|c|c|c|c|c}
\hline \hline Mark & $\begin{array}{c}\text { Yield } \\
\text { point } \\
\mathrm{kg} / \mathrm{mm}^{2}\end{array}$ & $\begin{array}{c}\text { Tensile } \\
\text { strength } \\
\mathrm{kg} / \mathrm{mm}^{2}\end{array}$ & $\begin{array}{c}\text { Yield } \\
\text { ratio } \\
\%\end{array}$ & $\begin{array}{c}\text { Elongation } \\
\%\end{array}$ & $\begin{array}{c}\text { Trans.* } \\
\text { Temp. } \\
{ }^{\mathrm{C}} \mathrm{C}\end{array}$ \\
\hline $\mathrm{A}$ & $38 \cdot 3$ & $51 \cdot 0$ & 75 & $41 \cdot 1$ & -70 \\
$\mathrm{~B}$ & $53 \cdot 9$ & $66 \cdot 6$ & 81 & $29 \cdot 1$ & -20 \\
$\mathrm{C}$ & $55 \cdot 0$ & $67 \cdot 1$ & 82 & $27 \cdot 7$ & -25 \\
\hline
\end{tabular}

* Width of $\mathrm{V}$ notch charpy impact specimens: $6 \mathrm{~mm}$

剂の相異による遷移温度の変化はほとえどないと考えて よい.なお熱延材の遷移温度が Nb 添加により高温側に 移動することは，Vanvorisの結果〉とよく一致する。

\section{4. 結 言}

$\mathrm{Nb}$ 系高降伏点鋼の添加刘としての Nb-C の実用性 を検討するため $3 \mathrm{~kg}$ および $100 \mathrm{~kg}$ 溶解の規模におい て, 溶鋼への溶解性や得られた鋼塊および鋼材の種々の 性質を調查し, Ferro-Nb 添加の場合と比較した。 その 結果 Nb-C は Ferro-Nb にくらべて鋼浴一の溶解速度 がかなり大きいことをみとめたが， $\mathrm{Nb}$ 歩留り，鋼塊中 での偏析，鋼材の組織および機械的性質におよぼす影響 などの点では Nb-C と Ferro-Nb との間に全く差の認 められないことを確認した。

$$
\text { 文 献 }
$$

1) E. E. Fletcher, $A . R$. Elsea and E. C. Bain: Trans. Quartery ASM, 54 (1961), p. 1

2) I. M. Mackenzie: Iron and Steel Inst., Special Report No. 81 (1963)

3 ) L. Meyer, C. Strassburger and D. SchauwINHOLD: Arch. Eisenhüttenw., 35(1964), p. 541

4) 成田, 小山: 鉄と鋼, 52 (1966) 4, p. 788

5 ) 金沢，中島：鉄と鋼，52(1966) 4, p. 792

6 ) 波木，川井，長谷部：住友金属，16（1964）2 April, p. 146

7) F. E. Vanvoris: Met. Progress, 82 (1962) 2, p. 84

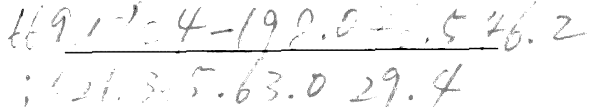

\section{(145) 8t 低周波誘導炉による粗 $\mathrm{Fe}-\mathrm{Ni}$} の脱硫について

（株）富山製錬所

$$
\begin{array}{r}
\text { 安田 汪. 山本 隆夫 } \\
\text { ○岡田 良一.甲谷 裕 }
\end{array}
$$

On the Desulphurization of Crude $\mathrm{Fe}-\mathrm{Ni}$ in the 8t Low Frequency Induction Furnace Hiroshi Yasuda, Takao Yамamoto Ryōichi OKADA and Yutaka KaBUTOYA

$$
\text { 1. 緒 }
$$

\section{言}

溶銑の脱硫法としては弧光炉による方法のほかに，脱 硫剂の粉末をガスで吹込む方法1)2) や取鍋傾注法 ${ }^{3)}$, 回 転炉法4)，振動取鍋法占)等があり，并れぞれ一長一短が ある。

その多くは熱源がなく温度降下が著しいので脱硫量に 限度がある。
当所では 40 年 4 月より坩堝型低周波誘導炉の強い電 磁擋找力を利用して粗 $\mathrm{Fe}-\mathrm{Ni}$ の脱硫を行なつているか， この方法では温度の調整が自由に行なわれるので脱硫量 を大きくすることができ，0.5\% を越える高硫のものか ら容易に $0.01 \%$ 以下に脱硫することができる.

以下にその操業方法について報告する.

\section{2. 装}

\section{$2 \cdot 1$ 装置概要}

設備の電力系統図および炉体断面と溶湯の運動状況を

Fig. 1 に示す.

付属設備としては冷却水の自動温度調節装置, 坩㶡故 障表示装置, 自動力率調整装置, 各種警報装置などがあ る.またライニングは酸性忓材のドライスタンプであ る.

\section{$2 \cdot 2$ 摚拌力と湯運動}

坩堝型誘導炉ではコイル電流による磁場と溶湯の誘導 電流のために Fig. 1 に示したような湯の運動を生じ， 湯面は盛上がり，強い擋找作用が行なわれる.

この盛上がり高さは負荷電力に比例し, 装入物の比重 周波数に反比例するほか, コイルと湯面の高さにも関係 する．湯がコイル面より低いと電力は全負荷がかから ず，またコイル面より上部の湯は盛上がりを抑制する.

また一般に溶解, 保温の場合に湯の運動が激しすきる とライニングの損耗を早めたり, 湯か酸化したり, 電力 損失をきたしたりするので，運動を抑える必要があるが 脱硫の場合は脱硫剂と湯の接触をよくするため湯運動が 激しく擋找されるほうがよい.

したがつて湯量と目的に応じてコイルを切替えて使用 する必要がある。

当所の炉における湯量と盛上がり高さおよび最高電圧 使用時の負荷電力の関係を Fig. 2 に示す.この関係は 坩堝の形状やライニングの損耗程度によつてちがつてく る。

\section{3. 操 業 方 法}

溶材および冷材を所要量装入し，下側コイルで溶解し てから上側コイルに切替え, 最高 2 次電圧を使用して楊 の盛上がりを大きくし, 脱硫郕をシュートで添加する.

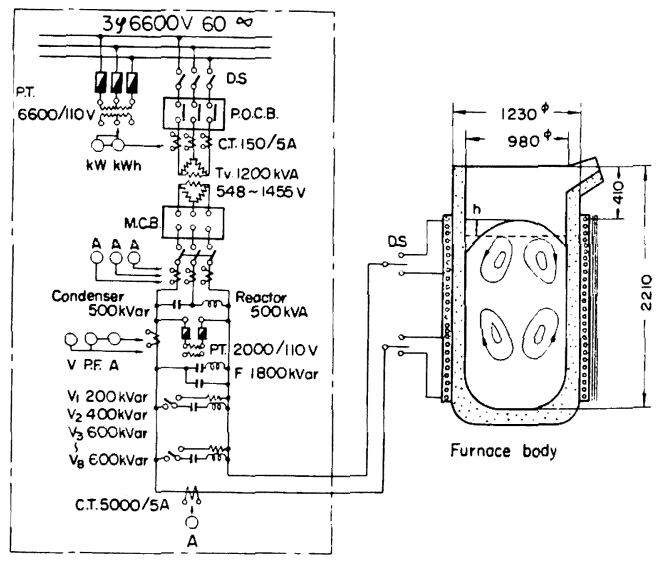

Fig. 1. Schematic diagram of $8 \mathrm{t}$ induction furnace. 